\title{
USGS Fire Science: Fire Danger Monitoring and Forecasting
}

The U.S. Geological Survey (USGS) has advanced the use of moderate-resolution satellite data in a decision support system for assessing national fire potential. Weekly updated digital images of the Normalized Difference Vegetation Index (NDVI), based on data acquired at 1-kilometer $(\mathrm{km})$ resolution (about 0.6 mile), have been used for the past 16 years as a means to assess live vegetation conditions for the purpose of rating fire danger. These images, produced and monitored through the growing season, portray the approximate time of greenup and senescence, as well as the relative amount and condition of growing plants.

Using the 16-year time series of NDVI, we are able to measure the historical minimum and maximum NDVI that have occurred during the growing season for every unique location. Each week we compare the current vegetation condition to the historical minimum and maximum values to determine the relative greenness. High relative greenness values indicate that the vegetation is near the maximum possible greenness for the specific vegetation type. Low values during the growing season indicate that the vegetation is under stress, possibly from drought, or is behind in development. Forest, shrub, and grassland vegetation with low relative greenness can be susceptible to fire ignition during the fire season.

The Fire Potential Index (FPI), which is derived by combining daily weather and vegetation condition information, can identify the areas most susceptible to fire ignition. The combination of relative greenness and weather information identifies the moisture condition of the live and dead vegetation. The weather information also identifies areas of low humidity, high

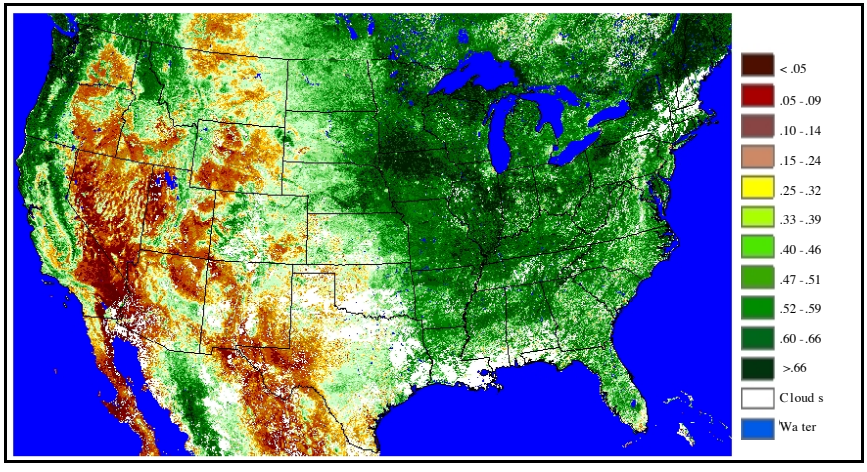

ive v

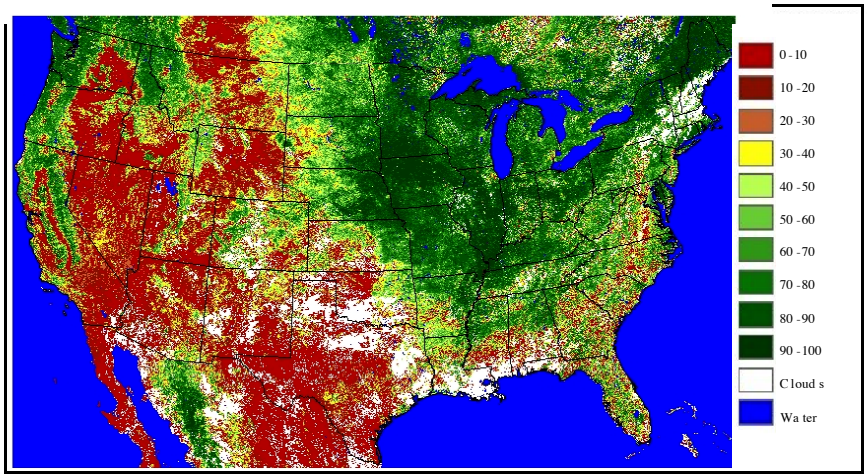

Relative Greenness

temperature, and no precipitation to identify areas most susceptible to fire ignition. The FPI enables local and regional fire planners to measure quantitatively fire ignition risk. The images show the vegetation condition, the relative greenness, and the resulting Fire Potential Index for August 12 , 2001, when a major outbreak of fires occurred in the western United States.

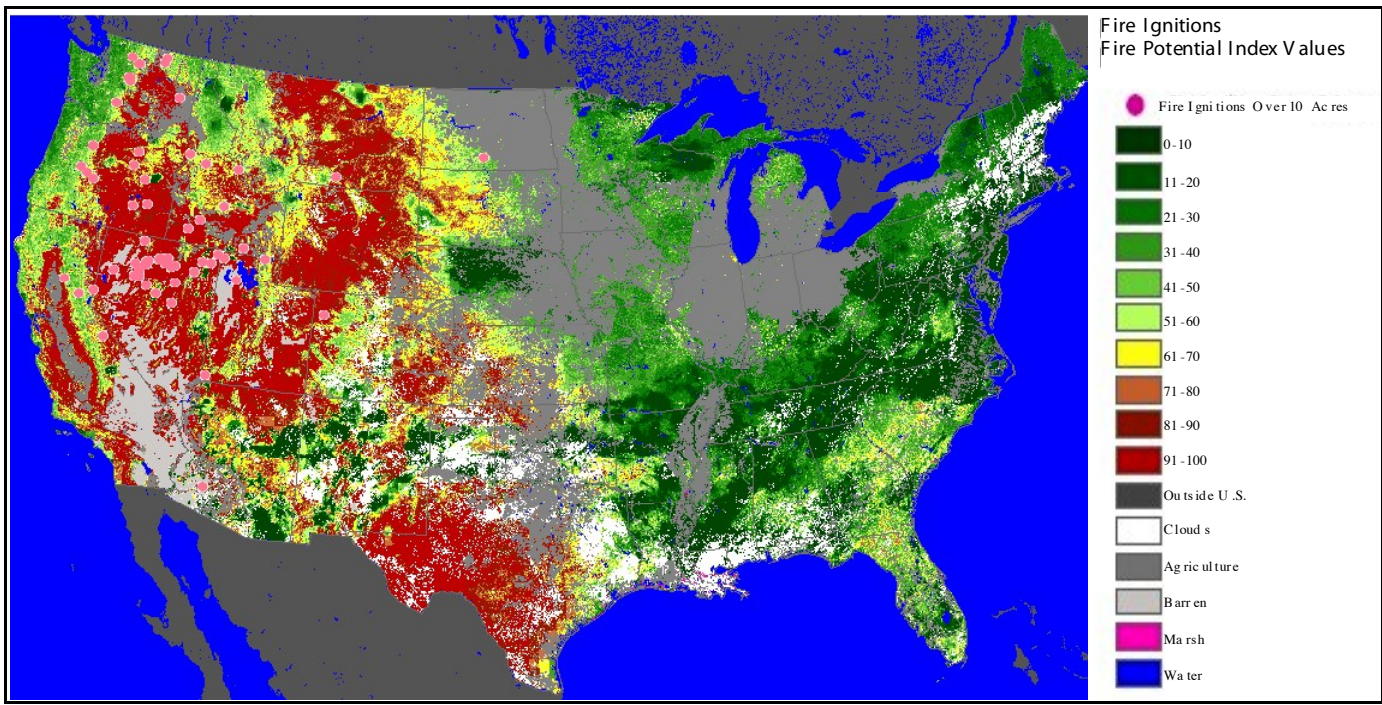

\section{For More Information}

Fire Science Web site: edc.usgs. gov/firescience

Jeff Eidenshink, Ph.D., or

Jacqueline Klaver

U.S. Geological Survey (USGS)

Center for Earth Resources

Observation and Science (EROS)

Mundt Federal Building

Sioux Falls, SD 57198-0001

Email: eidenshink@usgs.gov or jklaver@usgs.gov 